\title{
Strategic Human Resource Planning In Academia
}

Gregory Ulferts, University of Detroit Mercy, USA

Patrick Wirtz, University of Detroit Mercy, USA

Evan Peterson, University of Detroit Mercy, USA

\begin{abstract}
A strategic plan guides a college in successfully meeting its mission. Based on the strategic plan, a college can develop a human resource plan that will allow it to make management decisions in the present to support the future direction of the college.
\end{abstract}

The overall purpose of human resource management is to:

- ensure the organization has adequate human resources to meet it goals and operational plans

- allow the organization to stay apprised of the current social, economic, legislative and technological trends that affect human resources, and

- allow the organization to remain flexible to the dynamic changes in the environment.

Human resource management identifies the future needs of the college after analyzing the college's current human resources, the external labor market, and the future human resource environment in which the college will be operating. The analysis of issues external to the college, and developing scenarios about the future, are what distinguishes human resource management from operational planning. The basic questions to be answered for strategic human resource management are:

- Where are we going?

- Given the circumstances, how will we get there?

This article seeks to provide a framework for strategic human resource planning in academia.

Keywords: human resources, strategic planning

\section{INTRODUCTION}

n early discussions of human resource planning, Vetter (1967) defined it as "the process through which management determines how the organization should move from a current manpower arrangement to a more desired arrangement." By the use of strategic planning, management aims to have the right number and the right kind of employees, at the right place at the right time, performing actions which result in long-term benefits to both the individual and the organization. ${ }^{1}$

Modern human resource planning concerns the forecasting of the organization's human resource needs for the future and the planning required to meet those needs. It requires not only the establishment of objectives, but also the development and implementation of certain programs, such as staffing and training, to make sure people are present with the proper traits and skills when they are needed. ${ }^{2}$ Human resource planning also involves the collection of data, which can be used to evaluate program effectiveness and give notice when revision is needed. One of the objectives of planning is to facilitate organizational effectiveness, so it must be integrated with the

\footnotetext{
${ }^{1}$ S. Jackson and R. Schuler, "Human Resource Planning: Challenges for Industrial/Organizational Psychologists," American Psychologist 45, 2, 223-239 (1990).

2 "Human Resource Planning: Challenges for Industrial/Organizational Psychologists" at 223.
} 
organization's business objectives. Human resource planning continues to receive increased attention due to such factors as the development of new technology, changes in economic conditions, globalization, and a changing workforce. $^{3}$

\section{THE PROCESS}

The strategic human resource planning process is comprised of the following four steps, each of which will be discussed in detail:

- Assessing the current human resource capacity

- $\quad$ Forecasting human resource requirements

- Gap analysis

- Developing human resource strategies to support college strategies

\section{Assessing the current human resource capacity}

Based on the organization's strategic plan, the first step is to assess the current human resource capacity of the organization. The knowledge, skills, and abilities of current employees need to be identified. This identification can be done by developing a skills inventory for each employee.

It is important that the skills inventory go beyond the skills needed for the particular position. Instead, it should list all the skills each person has demonstrated. For example, community or volunteer activities may involve special skills that could be relevant to the organization. Education levels and certificates or additional training should also be included.

Once a performance assessment has been completed, it can be reviewed to determine if the person is ready and willing to take on more responsibility and to look at the person's current development plans.

\section{Forecasting human resource requirements}

The second step is to forecast human resource needs for the future based on the strategic goals of the organization. A realistic forecast of human resources involves the estimation of both supply and demand. Important questions that the forecasting should include are:

- How many faculty and staff will be required to achieve the strategic goals of the college?

- What jobs will need to be filled?

- What skill sets and credentials will people need?

When forecasting the possible demand for human resources, it is also vital to assess the challenges the college will have in meeting its staffing needs based on the external environment. This assessment must focus on how the external environment may impact human resource needs.

Modeling and forecasting can give management important information about the implications of different human resource strategies that can be used to support the goals of the organization. ${ }^{4}$ The modeling techniques can range from the relatively simple to the substantially complex. It is important that the model chosen be straightforward enough so that it will be better understood by management and the results will be more likely accepted. $^{5}$

Three types of modeling techniques are demand forecasting, integrated manpower planning, and supply

\footnotetext{
3 "Human Resource Planning: Challenges for Industrial/Organizational Psychologists" at 224.

${ }^{4}$ Bechet, T. and Maki, W. "Modeling and Forecasting: Focusing on People as a Strategic Resource," Human Resource Planning 10, 4, 209-217 (2002).

5 "Modeling and Forecasting: Focusing on People as a Strategic Resource" at 210.
} 
forecasting. Demand forecasting techniques include regression analysis, time series analysis, and simple percentage changes. Integrated models include linear programming, goal programming, and network models. Supply forecasting techniques include replacement charts and more popular methods based on a Markov model. ${ }^{6}$

\section{Gap analysis}

The next step is to determine the gap between where the college wants to be in the future and where it is now. The gap analysis includes identifying the number of faculty/staff and the skills and abilities required in the future. It is important to look at all of the college's human resource management practices to identify practices that could be improved or new practices needed to support the college's capacity to move forward. Questions to be answered include:

- What new jobs will we need?

- What new skills and abilities will be required?

- Do our present faculty/staff have the required skills?

- Are employees currently in positions that use their strengths?

- Do we have enough managers/supervisors?

- Are current human resource management practices adequate for future needs?

As suggested by Gregory Kesler, managing partner of Competitive Human Resources Strategies, LLC, ${ }^{7}$ in order to bridge the gap between strategic haves and have-nots, an approach is needed that: connects the people needs to the business needs, clarifies line ownership for the outcomes of human resources, guides the allocation of an investment in personnel to vital, strategic activities, drives organizational energy towards objectives that yield the greatest impact, defines the framework for the human resource function across all business units, and gives people a sense of purpose.

As suggested by Matthew Brush and Donald Ruse ${ }^{8}$, three principles guide the approach to the determination of what type of talent is required to execute business strategy.

- The first principle is that there must be a perceived connection to and an alignment with an organization's strategic business planning process.

- The second principle is that there must be a frame of mind that pushes decision making regarding an organization's talent portfolio.

- The third principle is an inquiry-centered approach that provides an answer to the following three questions: What key challenges must be addressed in order to attain desired performance? What critical business initiatives need to be executed in order to sufficiently address these key challenges? What capabilities and their corresponding talent types are critical to attain a competitive advantage?

Brush and Ruse go on to state that one approach to closing the talent gap is to examine the situation as a "build vs. buy" decision. It is suggested that buying is the best course of action when: the need for talent is urgent, the time/investment needed to obtain external talent is less than the time/investment needed to train internal talent, and when the required skill sets can only be found outside the company. ${ }^{9}$ Building decisions, on the other hand, are most appropriate when the timeframe can accommodate training of internal talent to satisfy organizational needs and the desired skills cannot be located externally. ${ }^{10}$

\footnotetext{
6 "Modeling and Forecasting: Focusing on People as a Strategic Resource" at 212.

${ }^{7}$ Kesler, G. "Four Steps to Building an HR Agenda for Growth: HR Strategy Revisited," Human Resource Planning 24-37.

${ }^{8}$ Brush, M. and Ruse, D. "Driving Strategic Success Through Human Capital Planning: How Corning Links Business and HR

Strategy to Improve the Value and Impact of Its HR Function," Human Resource Planning 28.1, 49-60.

9 "Driving Strategic Success Through Human Capital Planning" at 56.

10 "Driving Strategic Success Through Human Capital Planning" at 57.
} 


\section{Developing human resource strategies to support college strategies} the future:

There are five human resource strategies that a college may take advantage of in order to meet its needs for

- Restructuring strategies

- Training and development strategies

- Recruitment strategies

- $\quad$ Outsourcing strategies

- Collaboration strategies

Restructuring strategies

- $\quad$ Reducing staff either by termination or attrition

- Regrouping tasks to create well designed jobs

- Reorganizing work units to be more efficient

Restructuring strategies can encompass a number of tactics. For instance, employee reduction, either by termination or by attrition, may be undertaken. While termination style approaches can yield immediate results; it is important to remember that various can be associated with this approach, depending on applicable employment agreements. Attrition, on the other hand, is the process of not replacing employees when they leave. The viability of this approach is dependent upon the urgency with which employee reduction is needed. If this approach is chosen, jobs performed within the organization will have to be reorganized to ensure that all essential work of departing employees is covered. A careful assessment of the reorganized workloads of remaining personnel should be conducted, including an analysis of whether or not there are improved outcomes.

As noted by Gracie Ebadan and Diana Winstanley of Imperial College ${ }^{11}$ the downsizing and delayering programs implemented by organizations have left the survivors of this organizational change in a state of uncertainty regarding their continued employment. There are several methods that can be used to tackle the demoralizing effects of downsizing: career management review programs, assessment centers, open learning centers, and increased lateral movement. ${ }^{12}$

Sometimes existing faculty and staff may be willing to voluntarily reduce their hours, especially in situations that are merely temporary. Job sharing may be another option. The key to success is to ensure that the employees are satisfied with the arrangement and that it meets the needs of the organization. Excellent communication is a prerequisite for success.

Analysis may demonstrate that the organization has more resources in some areas of the college than others. This, in turn, would call for a redeployment of workers to areas with shortages. The training/development needs of the transferred individual need to be taken into account.

\section{Training and development strategies}

- $\quad$ Providing faculty/staff with training to take on new roles

- Providing current faculty and staff with development opportunities to prepare them for future jobs

Training and development needs can be met in a variety of ways. One approach is for the college/university to pay for faculty/staff to upgrade their skills. This may involve sending individuals to take courses or certificates. Many training and development needs can be met through cost effective techniques.

\footnotetext{
11 Ebadan, G. and Winstanley, D. "Downsizing, delayering and careers - The survivor's perspective," Human Resource Management Journal, 7, 1, 79-90.

12 "Downsizing, delayering and careers - The survivor's perspective" at 89.
} 
Human capital theory separates training into two types: general training and specific training. ${ }^{13}$ General training is any training provided by an organization that another organization can use. Specific training is any training provided by one organization that is specific to that organization. In other words, it is training that would have little use in other organizations. This distinction is important because the first step in analyzing the strategic value of any training program lies in a determination of whether it is general or specific.

Next, the training investment decision is based on the expected return from the specific training (S) plus expected return from general training $(G)$ less performance improvement value of the training to any competitors $\left(\mathrm{PI}_{\mathrm{c}}\right) .{ }^{14}$ The equation is summarized as follows: $\mathrm{S}+\mathrm{G}-\mathrm{PI}_{\mathrm{c}=}$. If $\mathrm{S}+\mathrm{G}>0$, the training can potentially achieve an internal ROI. In order for the training investment to be a strategic one, $S+G-\mathrm{PI}_{\mathrm{c}}$ must be greater than zero. When a training regimen is mostly specific, $\mathrm{S}+\mathrm{G}-\mathrm{PI}_{\mathrm{c}}$ is usually greater than zero, thus creating a strategic investment. Conversely, when training is for the most part general, $\mathrm{S}+\mathrm{G}-\mathrm{PI}_{\mathrm{c}}$ tends to be less than zero, thus failing to create a strategic investment.

Before an organization deems a training program to be a strategic interest, it must determine whether or not the training is truly strategic. If an organization intends to make training a core component of its competitive strategy, it needs to provide performance improvement and competitive advantage. The strategic training investment decision model is a tool that can be used to analyze the strategic potential of a training program. ${ }^{15}$

\section{Recruitment strategies}

- Recruiting new faculty/staff with the skills and abilities that our college will need in the future

For strategic human resource planning, each time the college recruits it should be looking at the requirements from a strategic perspective keeping in mind that recruitment involves the creation of a pool of qualified applicants from a variety of sources. ${ }^{16}$

Recruitment can be considered the way an employer initially collects information about potential job candidates. The choice of recruitment, in turn, affects the size, quality, and influx of applicants.

When deciding upon a proper recruitment strategy to pursue, organizations seem to be faced with a trade off. ${ }^{17}$ On the one hand, an organization may need to hire employees for a position as soon as possible. On the other hand, a speedy approach may not yield employees with the degree of quality the organization desires. Since the quality of an applicant's match and the hiring speed will both be important to some organizations and not others, recruitment choices can thus be expected to differ by firm characteristics and desired skill levels.

\section{Outsourcing strategies}

- Using external individuals or organizations to do some tasks, many organizations look outside their own human resource pool and contract for certain skills. This is particularly helpful for accomplishing specific, specialized tasks that don't require ongoing full-time work. Some organizations outsource human resource activities.

As mentioned in an article by Recruitment Enhancement Services, ${ }^{18}$ a solution to the problem posed by the significant expenses associated with traditional recruitment is Recruitment Process Outsourcing (RPO). RPO is the transfer of the talent hiring process from an organization's Human Resource department to a supplier/partner whose core competency lies in that very area. RPO can result in a number of benefits to an organization, including:

\footnotetext{
${ }^{13}$ Krohn, R. "Training as a Strategic Investment," Advances in Developing Human Resource 2, 63-74 (2000).

14 "Training as a Strategic Investment" at 66.

15 "Training as a Strategic Investment" at 74.

${ }^{16}$ Hernandez, V. and Franklin, G. "Human Resource Management Basics: Small Versus Large Firm Practices," Proceedings CD, Association for Small Business \& Entrepreneurship, 61-75 (2004).

${ }^{17}$ Devaro, J. "Employer Recruitment Strategies and the Labor Market Outcomes of New Hires," Economic Inquiry 43, 2, 263282 (2005).

${ }^{18}$ Siegel, B. “The Business Case for Recruitment Process Outsourcing," Recruitment Enhancement Services 6-24 (2005).
} 
improving the quality of new hires, improving the efficiency and effectiveness of the hiring process, and providing hiring process expertise and flexibility within the staffing function.

\section{Collaboration strategies:}

Finally, the strategic human resource planning process may lead to indirect strategies that go beyond the borders of the organization. This collaboration with another organization or organizations may provide for better success at dealing with a shortage of certain skills. Types of collaboration could include:

- Working with other organizations in the development of promising individuals.

- $\quad$ Sharing the costs of training/development.

- $\quad$ Allowing faculty/staff to visit other organizations to gain skills and insight.

According to an article from the University of Alicante, ${ }^{19}$ cooperative partnerships are increasingly becoming one of the main strategic tools of an organization. However, such strategic alliances have a surprisingly high failure rate, which is often due to problems with the management of the joint operation of the organizations. These operational problems could include weaknesses in the design of the alliance, strategy formulation, coordination of partners' activities, and conflict resolution.

Despite the many challenges that present themselves when a strategic alliance is utilized, the likelihood of success can be increased through an effective cooperation strategy. A cornerstone strategy is a management scheme that attempts to obtain unreserved collaboration by all personnel involved. In addition, it is important that all personnel involved work for the benefit of the entire association itself, rather than for the benefit of their respective organizations. ${ }^{20}$ This can be difficult because many organizations can be resistant to change. However, techniques like negotiation, communication, support, and participation can help to overcome this resistance.

\section{DOCUMENTATION}

Once the strategies for human resources in the college have been developed they should be documented in a human resource plan. This is a brief document which states the key assumptions and the resulting strategies along with who has responsibility for the strategies and the timelines for implementation.

A business-unit people plan is to human resource planning what competitive strategy is to overall business planning. ${ }^{21}$ In addition, first-class development plans are dynamic, living documents. ${ }^{22}$ Thus, if the requirement of a new skill is identified, the circumstances change, or unforeseen opportunities suddenly arise, the plan can be modified to take accordingly.

\section{IMPLEMENTATION}

Once the human resource strategic plan is complete it must be properly implemented. The most effective and efficient plan in history can not only be useless if not implemented, it can also be useless if it is implemented improperly or without sufficient means to measure its performance after actual implementation.

\section{Agreement with the plan}

First and foremost, it is important that there be agreement and ownership with the strategic human resources plan being implemented. ${ }^{23}$ Specifically, senior management must be personally engaged in the project and

\footnotetext{
${ }^{19}$ Lajara, B., Lillo, F. and Sempere, V. "The Role of Human Resource Management in the Cooperative Strategy Process," Human Resource Planning 34-44.

20 "The Role of Human Resource Management in the Cooperative Strategy Process" at 36.

21 "Four Steps to Building an HR Agenda for Growth: HR Strategy Revisited" at 28.

${ }^{22}$ Stringer, R. and Cheloha, R. "The Power of a Development Plan," Human Resource Planning, 10-17.

23 "The Power of Development Plan" at 13.
} 
must show their commitment to it. ${ }^{24}$ At first glance this may seem a redundant step, as many individuals likely have been involved with the plan since the time of its initial consideration. However, it is common knowledge and a formal tenet of doing business that initial plans are always subject to change. It is likely the proposed plan was subjected to numerous revisions and reconsiderations, to ensure it would achieve maximum effectiveness and fit within the organization upon final implementation. Thus, some personnel within the organization may be unaware of certain changes. The act of bringing all the information relating to the plan of action together for a final confirmation not only ensures all personnel involved are aware of what the next steps will be, but it is also ensures that the organization has a well laid plan from which to proceed.

\section{Communication}

The strategic human resource plan needs to be communicated throughout the organization. This communication should articulate the following:

- $\quad$ how the plan ties to the college's overall strategic plan

- what changes in human resource management policies, practices, and activities will be made to support the strategic plan

- how any changes in human resource management will impact on faculty/staff including a timeframe if appropriate

- how faculty/staff will be supported through any changes, and

- $\quad$ how the college will be different in the future.

It is difficult to communicate too much (but all too easy to communicate too little), especially when changes involve people.

\section{Compliance}

It is vital that an organization ensure its proposed human resource planning strategy complies with existing laws, regulations and contractual obligations. Depending on what industry the organization is in, this might appear to be a daunting task. Organizations may need to be aware of laws and regulations in corporate law, agency law, labor law, antitrust law, contract law, etc. In addition to all applicable domestic laws, if an organization enters into an outsourcing relationship or strategic alliance with an organization in another country, it must also be aware of the laws within that country as well. This may prove to create a highly complex situation when dealing with international legal systems vastly different from the organization's home country.

Needs

It is also important to consider the implications for space, equipment, and other existing resources that the human resource plan will have upon the organization. For example, if the plan requires the hiring of additional personal, the organization must ensure it has sufficient office space, supplies, and funds to accommodate the additional employees. Also, if the organization chooses to hire or is required to hire an employee or employees with disabilities, the organization may have to make physical changes to its facility in order to comply with laws relating to disabled employees. This may entail the installation of wheelchair ramps, automatic doors, and the addition of handicapped parking spaces. It may also require the purchase of specialized equipment. If the proposed human resource change is significant, it may also be in the organization's interests to provide other services for the comfort of the employees, such as on-site eating facilities, athletic facilities, or even child care services.

\section{Evaluation}

Human resource plans need to be updated on a regular basis. We will need to establish the information necessary to evaluate the success of the new plan. Benchmarks need to be selected and measured over time to determine if the plan is successful in achieving the desired objectives.

24 "The Role of Human Resource Management in the Cooperative Strategy Process" at 37. 
A report from the U.S. Office of Personnel Management ${ }^{25}$ gives several examples of how human resource management performance can be measured. For instance, benchmarks are systematic processes of measuring an organization's products, services, and practices against those of other organizations who are considered to be industry leaders. An effective evaluation tool is the balanced scorecard: a framework that can be used to translate strategies into operations terms by examining a range of viewpoints such as financial, customer, internal, and growth.

As noted in "Human Resource Planning: Changes for Industrial/Organizational Psychologists," the evaluation phase involves assessing how well objectives were achieved, if at all. ${ }^{26}$ Depending on whether the planning objectives are short-term or long-term, it is feasible to determine whether the number of applicants or number of new hires meets the goal established by the organization.

\section{SUMMARY}

At an operational level, colleges put in place human resource management practices to support faculty and staff in achieving their day-to-day goals. Whether it's determining how many staff are needed to deliver services over the next year or how performance will be monitored, the human resource management practices and activities need to be strategically planned in order to answer the question, "Where is our college going and how will it get there?"

\section{AUTHOR INFORMATION}

Dr. Gregory Ulferts is a Professor of Decision and Systems Sciences in the College of Business Administration. His scholarly activities have included research and publication on various topics related to management information systems, financial management, decision sciences, small business administration, and international business. Dr. Ulferts has served as a consultant in business and government in areas such as strategic and technology planning, operations and procurement management, analysis and design of systems, and business development.

Mr. Patrick Wirtz is an Associate Professor of Accounting in the College of Business Administration. His scholarly activities have included research and publication on various topics related to accounting, ethics, systems, and business management. Mr. Wirtz is a Certified Public Accountant and has an active accounting practice.

Evan Peterson, JD, MBA has taught as an adjunct professor in the College of Business Administration at the University of Detroit Mercy. He has published in the Journal of Business \& Economics Research. Mr. Peterson's other areas of publication include scholarly articles on supply chain management, technology, decision making and innovative teaching methods. His current research interests focus on the effects of legal regulation on corporate culture and the regulatory framework surrounding securities law.

\section{REFERENCES}

1. Bechet, T. and Maki, W. "Modeling and Forecasting: Focusing on People as a Strategic Resource," Human Resource Planning 10, 4 209-217 (2002).

2. Brush M. and Ruse, D. "Driving Strategic Success Through Human Capital Planning: How Corning Links Business and HR Strategy to Improve the Value and Impact of Its HR Function," Human Resource Planning 28.1, 49-60.

3. Devaro J. "Employer Recruitment Strategies and the Labor Market Outcomes of New Hires," Economic Inquiry 43, 2, 263-282 (2005).

4. Ebadan, G. and Winstanley, D. "Downsizing, delayering and careers - The survivor's perspective," Human Resource Management Journal, 7, 1, 79-90.

5. Hernandez, V. and Franklin, G. "Human Resource Management Basics: Small Versus Large Firm Practices,” Proceedings CD, Association for Small Business \& Entrepreneurship, $61-75$ (2004).

\footnotetext{
25 “Strategic Human Resources Management: Aligning with the Mission,” U.S. Office of Personnel Management 1-42 (1999).

26 "Human Resource Planning: Challenges for Industrial/Organizational Psychologists" at 227.
} 
6. Jackson, S. and Schuler, R. "Human Resource Planning: Challenges for Industrial/Organizational Psychologists," American Psychologist 45, 2, $223-239$ (1990).

7. Kesler, G. "Four Steps to Building an HR Agenda for Growth: HR Strategy Revisited," Human Resource Planning 24-37.

8. Krohn, R. "Training as a Strategic Investment," Advances in Developing Human Resource 2, 63-74 (2000).

9. Lajara, B., Lillo, F. and Sempere, V. "The Role of Human Resource Management in the Cooperative Strategy Process," Human Resource Planning 34-44.

10. Siegel, B. "The Business Case for Recruitment Process Outsourcing," Recruitment Enhancement Services 6-24 (2005).

11. "Strategic Human Resources Management: Aligning with the Mission," U.S. Office of Personnel Management 1-42 (1999).

12. Stringer R., and Cheloha, R. "The Power of a Development Plan," Human Resource Planning, 10-17.

\section{NOTES}


NOTES 